\title{
Structure and magnetic properties of $\left(\mathrm{Nd}_{1-x} \mathrm{Er}_{x}\right)_{3} \mathrm{Fe}_{25} \mathrm{Cr}_{4.0}(0 \leqslant x \leqslant 0.8)$ compounds
}

\author{
Luo Hongzhi ${ }^{1,2}$, Jia Lin ${ }^{1,3}$, Li Yangxian ${ }^{2}$, Meng Fanbin ${ }^{2}$, \\ Shen Jiang ${ }^{3}$, Chen Nanxian ${ }^{3}$, Wu Guangheng ${ }^{1}$ and Yang Fuming ${ }^{1}$ \\ ${ }^{1}$ State Key Laboratory of Magnetism, Institute of Physics, Chinese Academy of Sciences, \\ PO Box 603, Beijing, 100080, People's Republic of China \\ ${ }^{2}$ School of Material Science and Engineering, Hebei University of Technology, Tianjin, \\ 300130, People's Republic of China \\ ${ }^{3}$ Institute of Physics, Beijing University of Science and Technology, Beijing, 100083, \\ People's Republic of China
}

Received 23 April 2004

Published 15 September 2004

Online at stacks.iop.org/JPhysD/37/2632

doi:10.1088/0022-3727/37/19/003

\begin{abstract}
The structure and magnetic properties of $\left(\mathrm{Nd}_{1-x} \mathrm{Er}_{x}\right)_{3} \mathrm{Fe}_{25} \mathrm{Cr}_{4.0}$ compounds with $x=0-0.8$ have been investigated using $\mathrm{X}$-ray powder diffraction (XRD) and magnetic measurements. It has been found that all the compounds crystallize in a $\mathrm{Nd}_{3}(\mathrm{Fe}, \mathrm{Ti})_{29}$-type structure. Substitution of $\mathrm{Er}$ for $\mathrm{Nd}$ leads to a contraction of the unit-cell volume. The Curie temperature, $T_{\mathrm{c}}$, and the saturation magnetization, $M_{\mathrm{s}}$, of $\left(\mathrm{Nd}_{1-x} \mathrm{Er}_{x}\right)_{3} \mathrm{Fe}_{25} \mathrm{Cr}_{4.0}$ decrease monotonically with increasing Er content. The easy magnetization direction (EMD) of $\mathrm{Nd}_{3} \mathrm{Fe}_{25} \mathrm{Cr}_{4.0}$ at room temperature is close to the [040] direction but may be a little out of the basal plane. With increasing Er content, the EMD changes closer to the [40-2] direction and the tilt angle increases. Both the XRD patterns and ac susceptibility indicate the appearance of a spin reorientation for $x=0-0.4$ as the temperature decreases from room temperature to $77 \mathrm{~K}$. The spin reorientation temperature, $T_{\mathrm{sr}}$, increases monotonically with increasing Er content from $158 \mathrm{~K}$ for $x=0$ to $198 \mathrm{~K}$ for $x=0.4$. A first order magnetization process (FOMP) occurs for all the compounds, and the critical field of the FOMP decreases with increasing Er content from $6.6 \mathrm{~T}$ for $x=0$ to $2.0 \mathrm{~T}$ for $x=0.7$.
\end{abstract}

\section{Introduction}

Collocott et al [1] found a new phase in the iron-rich corner in the $\mathrm{Nd}-\mathrm{Fe}-\mathrm{Ti}$ ternary phase diagram, which was later identified to be of $\mathrm{Nd}_{3}(\mathrm{Fe}, \mathrm{Ti})_{29}$-type structure with monoclinic symmetry and space group $A_{2 / m}$ [2]. Since then, much attention has been paid to the $\mathrm{R}_{3}(\mathrm{Fe}, \mathrm{M})_{29}$ compounds, where $\mathrm{R}$ stands for rare-earth and $\mathrm{M}$ for stabilizing element. A series of novel $\mathrm{R}_{3}(\mathrm{Fe}, \mathrm{M})_{29}$ compounds and their interstitial compounds have been synthesized for $\mathrm{R}=\mathrm{Sm}, \mathrm{Ce}, \mathrm{Pr}, \mathrm{Nd}, \mathrm{Y}, \mathrm{Gd}, \mathrm{Tb}$ and $\mathrm{M}=\mathrm{Mo}, \mathrm{Ti}, \mathrm{Cr}, \mathrm{Mn}, \mathrm{V}$, etc [3-8]. Yang et al [9] and $\mathrm{Hu}$ et al [10] have synthesized $\mathrm{Sm}_{3}(\mathrm{Fe}, \mathrm{Ti})_{29} \mathrm{~N}_{y}$ and $\mathrm{Sm}_{3}(\mathrm{Fe}, \mathrm{Ti})_{29} \mathrm{C}_{y}$ compounds, respectively, which exhibit outstanding intrinsic magnetic properties. Subsequently, Li et al [11] have synthesized $\mathrm{Sm}_{3} \mathrm{Fe}_{12.1} \mathrm{Co}_{16} \mathrm{Mo}_{0.9}$, which is a very promising candidate for novel rare-earth permanent magnetic materials. However, the exact nature of the magnetic anisotropy of these compounds is still not quite clear, and so it is of great value to study the structure and magnetic properties of the $3: 29$ series. It is well known that the $\mathrm{Nd}_{3}(\mathrm{Fe}, \mathrm{Ti})_{29}$-type structure is an intermediate structure between the rhombohedral $\mathrm{Th}_{2} \mathrm{Zn}_{17}$ $(2: 17 \mathrm{R})$ and tetragonal $\operatorname{ThMn}_{12}(1: 12)$ structures with a ratio $1: 1$. However, so far $\mathrm{R}_{3}(\mathrm{Fe}, \mathrm{M})_{29}$ compounds with $\mathrm{Nd}_{3}(\mathrm{Fe}, \mathrm{Ti})_{29}$ type structures, $\mathrm{R}$ being a heavy rare-earth element heavier than Ho, have not been synthesized.

The magnetocrystalline anisotropy of the R-Fe intermetallic compounds results from the contribution of both $\mathrm{R}$ - and Fe-sublattices. A study of the compound $\mathrm{Y}_{3}(\mathrm{Fe}, \mathrm{Ti})_{29}$ 


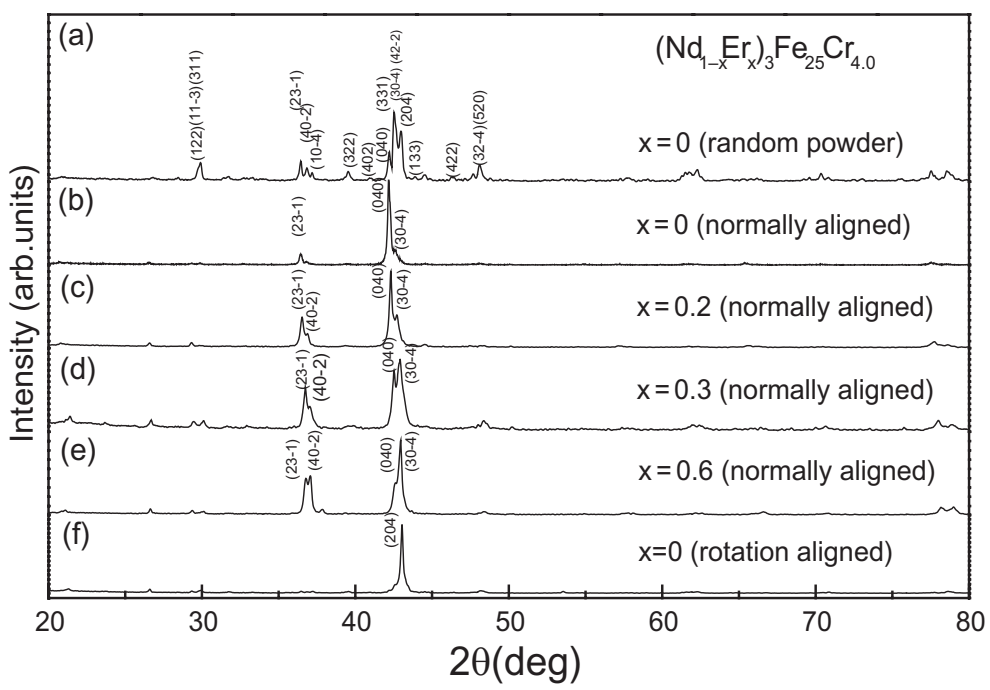

Figure 1. XRD patterns of the random and magnetically aligned powder samples of the $\left(\mathrm{Nd}_{1-x} \mathrm{Er}_{x}\right)_{3} \mathrm{Fe}_{25} \mathrm{Cr}_{4.0}$ compounds.

has indicated that the magnetocrystalline anisotropy arising from the Fe sublattice favours the [40-2] direction [12]. The anisotropy of the $\mathrm{R}$ sublattice in $\mathrm{R}_{3}(\mathrm{Fe}, \mathrm{M})_{29}$ arises from the crystal field interaction at the $\mathrm{R}$ sites. In the $\mathrm{R}_{3}(\mathrm{Fe}, \mathrm{Ti})_{29}$-type structure, there are two different $\mathrm{R}$ sites with opposite signs of the second order crystal field parameter $A_{20}$. When $A_{20}$ is negative at a site, a rare-earth with a positive second-order Stevens coefficient, $\alpha_{\mathrm{J}}(\mathrm{Sm}, \mathrm{Tm}, \mathrm{Er}, \mathrm{Yb})$, will contribute uniaxial anisotropy, while for positive $A_{20}$, a rare-earth with a negative $\alpha_{\mathrm{J}}(\mathrm{Pr}, \mathrm{Nd}, \mathrm{Tb}, \mathrm{Dy}, \mathrm{Ho})$ will exhibit uniaxial anisotropy [13]. So it is expected that the substitution of one rare-earth for the other with different $\alpha_{\mathrm{J}}$ will influence the magnetic properties, especially the magnetocrystalline anisotropy in $\mathrm{R}_{3}(\mathrm{Fe}, \mathrm{Ti})_{29}$.

In this paper, the effect of substitution of $\mathrm{Er}$ for $\mathrm{Nd}$ on the structure and magnetic properties, especially the magnetocrystalline anisotropy, of $\mathrm{Nd}_{3}(\mathrm{Fe}, \mathrm{Cr})_{29}$ is studied.

\section{Experimental}

A series of $\left(\mathrm{Nd}_{1-x} \mathrm{Er}_{x}\right)_{3} \mathrm{Fe}_{25} \mathrm{Cr}_{4.0}$ compounds with $x=0-1.0$ were prepared by arc melting the constituent elements in a high purity argon atmosphere. The purity of the starting elements was higher than $99.9 \%$. All the ingots were remelted at least four times for homogenization. The ingots were wrapped in molybdenum foil and sealed in a quartz tube and then annealed at $1293 \mathrm{~K}$ for $72 \mathrm{~h}$ under the protection of an argon atmosphere, followed by water quenching. $\mathrm{X}$-ray powder diffraction (XRD) with $\mathrm{Cu}-\mathrm{K}_{\alpha}$ radiation was used to check the structure and to measure the lattice parameters of the compounds. Thermomagnetic curves (TMA) were measured in a vibrating-sample magnetometer (VSM) with a field of $0.05 \mathrm{~T}$ to check the single phase characteristic and to measure the Curie temperature $\left(T_{\mathrm{c}}\right)$. The Curie temperature was derived from the $M^{2}-T$ curves by extrapolating $M^{2}$ to zero. The magnetization curves were measured using a superconducting quantum interference device (SQUID) magnetometer with an applied field of up to $7 \mathrm{~T}$ or using a Quantum Design PPMS-14 system with a field up to $14 \mathrm{~T}$. The saturation magnetization $\left(M_{\mathrm{s}}\right)$ was determined from $M-(1 / H)$ curves by extrapolating
$1 / H$ to zero. Ac susceptibility measurements were carried out from $77 \mathrm{~K}$ to room temperature.

In order to examine the magnetocrystalline anisotropy at room temperature, finely powdered particles were mixed with epoxy resin and packed in a cylindrical plastic tube. For normal alignment, the plastic tube was put in a field of about $1 \mathrm{~T}$ with the cylinder axis parallel to the field direction, so that the cylindrical axis was the easy magnetization direction (EMD). For alignment of rotation, the tube was rotated around its cylindrical axis, which was perpendicular to the applied field, and so the cylindrical axis was the hard magnetization direction (HMD).

\section{Results and discussion}

Both XRD and TMA reveal that all the $\left(\mathrm{Nd}_{1-x} \mathrm{Er}_{x}\right)_{3} \mathrm{Fe}_{25} \mathrm{Cr}_{4.0}$ compounds for $x=0-0.8$ are substantially $3: 29$ single phase except for $\mathrm{Nd}_{0.6} \mathrm{Er}_{2.4} \mathrm{Fe}_{25} \mathrm{Cr}_{4.0}$, which contains a small amount of the $1: 12$ phase. As an example, figure 1(a) shows XRD patterns taken from randomly oriented powder samples of $\mathrm{Nd}_{3} \mathrm{Fe}_{25} \mathrm{Cr}_{4.0}$, which can be well indexed based on the monoclinic $\mathrm{Nd}_{3}(\mathrm{Fe}, \mathrm{Ti})_{29}$-type structure of space group $A_{2 / m}$. The lattice parameters calculated from the XRD patterns are listed in table 1. It can be seen that the lattice constants $a, b$, and $c$ and the unit cell volume, $V$, show a tendency to decrease with increasing Er content. This is due to the fact that $\mathrm{Er}$ has a smaller atomic radius than that of $\mathrm{Nd}$. Single phase $\left(\mathrm{Nd}_{1-x} \mathrm{Er}_{x}\right)_{3} \mathrm{Fe}_{25} \mathrm{Cr}_{4.0}$ compounds with the $\mathrm{Nd}_{3}(\mathrm{Fe}, \mathrm{Ti})_{29}$-type structure could not be synthesized for $x=0.9$ and 1.0.

In order to examine room temperature magnetocrystalline anisotropy, XRD patterns of the normally aligned powder samples of the $\left(\mathrm{Nd}_{1-x} \mathrm{Er}_{x}\right)_{3} \mathrm{Fe}_{25} \mathrm{Cr}_{4.0}$ compounds were measured, as shown in figure 1(b)-(e). Compared with the randomly aligned powder sample with $x=0$ (figure 1(a)), it can be seen from figure 1(b) that for the normally aligned sample, the intensity of (040) reflection increases obviously, while those of the $(23-1),(40-2)$, and (30-4) reflections decrease, and other reflections disappear. It is well known that the $3: 29$-type structure can be derived by replacing a fraction of the $\mathrm{Ca}$ sites in the $\mathrm{CaCu}_{5}$-type structure by a pair of transition 
Table 1. Structure and magnetic parameters of $\left(\mathrm{Nd}_{1-x} \mathrm{Er}_{x}\right)_{3} \mathrm{Fe}_{25} \mathrm{Cr}_{4.0}$ compounds.

\begin{tabular}{lllllllll}
\hline Composition & $a(\AA)$ & $b(\AA)$ & $c(\AA)$ & $V\left(\AA^{3}\right)$ & $T_{\mathrm{c}}(\mathrm{K})$ & $T_{\mathrm{sr}}(\mathrm{K})$ & $M_{\mathrm{s}}\left(\mathrm{emu} \mathrm{g}^{-1}\right)$ & $B_{\mathrm{cr}}(\mathrm{T})$ \\
\hline$x=0$ & 10.607 & 8.556 & 9.717 & 875.5 & 418 & 158 & 113.9 & 6.6 \\
$x=0.1$ & 10.629 & 8.559 & 9.686 & 874.8 & 415 & 166 & 111.8 & 6.2 \\
$x=0.2$ & 10.620 & 8.554 & 9.683 & 873.3 & 410 & 173 & - & - \\
$x=0.3$ & 10.608 & 8.534 & 9.698 & 871.5 & 408 & 185 & 96.9 & 5.1 \\
$x=0.4$ & 10.594 & 8.509 & 9.691 & 867.0 & 406 & 198 & - & 77.6 \\
$x=0.5$ & 10.583 & 8.510 & 9.680 & 865.3 & 401 & - & - & 3.6 \\
$x=0.6$ & 10.571 & 8.498 & 9.672 & 862.5 & 399 & - & 61.9 & 2.0 \\
$x=0.7$ & 10.560 & 8.480 & 9.646 & 857.4 & 394 & - & - & - \\
$x=0.8$ & 10.556 & 8.486 & 9.655 & 858.6 & 380 & - & - & \\
\hline
\end{tabular}

metal atoms (dumbbell) along the hexagonal axis of the $\mathrm{CaCu}_{5}$ structure. According to the transformation relationship between the $3: 29$-type and 1:5-type structures [12], it can be seen that the $(040),(23-1),(40-2)$, and $(30-4)$ reflections in the $3: 29$-type structure correspond to the $(1-10),(140),(110)$, and (22-1) reflections in the 1:5-type structure, respectively. Among them, the [1-10], [140], and [110] directions are in the basal plane in the $1: 5$ type structure, whereas the [22-1] direction makes a tilt angle with respect to the basal plane [14]. This suggests that the EMD of the $\mathrm{Nd}_{3} \mathrm{Fe}_{25} \mathrm{Cr}_{4.0}$ compound is very close to the [040] direction, but it is a little out of the basal plane of the $1: 5$ structure.

Figure 1(f) shows the XRD pattern of a rotation-alignment sample of the $\mathrm{Nd}_{3} \mathrm{Fe}_{25} \mathrm{Cr}_{4.0}$ compound. It is clear that only the (204) reflection is retained and all the other reflections have almost disappeared. This further confirms that the HMD of the $\mathrm{Nd}_{3} \mathrm{Fe}_{25} \mathrm{Cr}_{4.0}$ compound is in the [204] direction ([001] direction in the 1:5-type structure), and the HMDs of these compounds can be obtained by the rotation-alignment method.

As the Er content ( $x$ ) increases (see figure 1(c)-(e)), the intensity of the (40-2) and (30-4) reflections increases significantly, and the intensity of the (040) reflection decreases, whereas the $(23-1)$ reflection increases first with increasing Er content from 0 to 0.3 , through a maximum at $x=0.3$ and then decreases with further increasing $x$, which shows a complex change in the anisotropy of the $\left(\mathrm{Nd}_{1-x} \mathrm{Er}_{x}\right)_{3} \mathrm{Fe}_{25} \mathrm{Cr}_{4.0}$ compounds with Er substitution. It is worth noting that with increasing Er content, the EMD of the $\left(\mathrm{Nd}_{1-x} \mathrm{Er}_{x}\right)_{3} \mathrm{Fe}_{25} \mathrm{Cr}_{4.0}$ compounds is most likely to change from the direction close to the [040] direction to another close to the [40-2] direction, and make a larger tilt angle with respect to the basal plane of the $1: 5$ structure.

It is well accepted that in rare-earth (R)-transition metal (T) intermetallic compounds, in the first approximation, the rare-earth sublattice anisotropy constant, $K_{1}^{\mathrm{R}}$, is determined by the product of the second order crystal field parameter, $A_{20}$, and the second order Stevens coefficient, $\alpha_{\mathrm{J}}$. It can be expressed by

$$
K_{1}^{\mathrm{R}}=\frac{1}{2} \alpha_{\mathrm{J}}\left\langle r^{2}\right\rangle\left\langle 3 J^{2}-J(J+1)\right\rangle A_{20},
$$

where the quantities in angular brackets denote the expectation values. It has been reported that, in $\mathrm{R}_{3}(\mathrm{Fe}, \mathrm{Ti})_{29}$ compounds, the crystal field parameters $A_{20}$ have opposite signs for the two $\mathrm{R}$ sites, namely $A_{20}<0$ for the $4 \mathrm{i}$ sites (2:17-like) and $A_{20}>0$ for the $2 \mathrm{a}$ sites $(1: 12$-like) [13]. From the model of Courtois et al [12], one knows that the anisotropy resulting from $\mathrm{Nd}$ atoms with $\alpha_{\mathrm{J}}<0$ favours the easy plane.

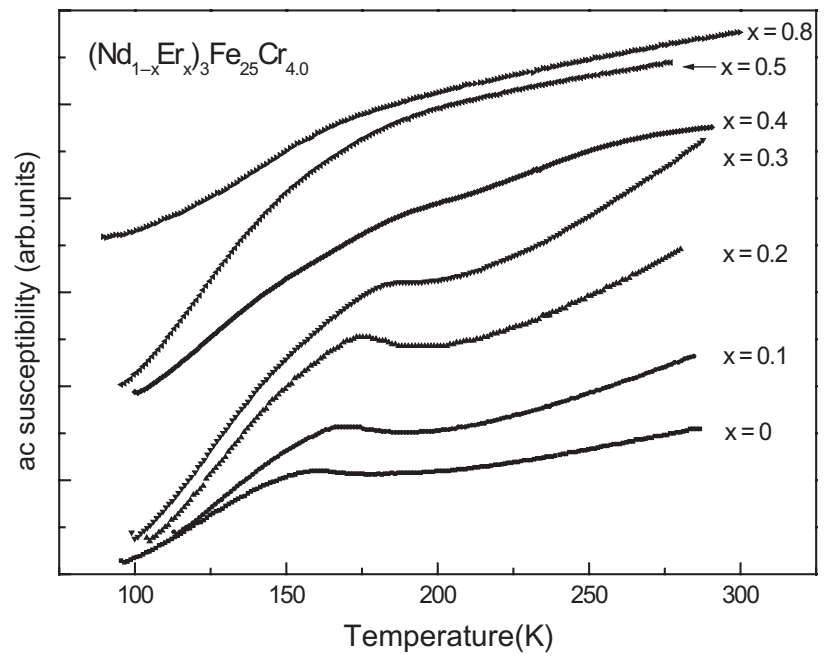

Figure 2. Ac susceptibility against temperature for $\left(\mathrm{Nd}_{1-x} \mathrm{Er}_{x}\right)_{3} \mathrm{Fe}_{25} \mathrm{Cr}_{4.0}$ compounds.

Considering that the radius of the Er atom is smaller and favours the $4 \mathrm{i}$ site, the anisotropy resulting from Er atoms with $\alpha_{\mathrm{J}}>0$ favours the easy axis, namely the [204] direction [15]. Therefore, it is easy to understand that the tilt angle made by the EMD of the $\left(\mathrm{Nd}_{1-x} \mathrm{Er}_{x}\right)_{3} \mathrm{Fe}_{25} \mathrm{Cr}_{4.0}$ compounds with respect to the basal plane of the $1: 5$ structure increases with Er content.

The temperature dependence of the real component, $\chi^{\prime}$, of the ac susceptibility for the $\left(\mathrm{Nd}_{1-x} \mathrm{Er}_{x}\right)_{3} \mathrm{Fe}_{25} \mathrm{Cr}_{4.0}$ compounds was measured in the temperature region from $77 \mathrm{~K}$ to room temperature and is shown in figure 2 . It can be seen that for the samples with $x=0-0.4$, an obvious anomaly can be observed in the curves at certain temperatures. Such an anomaly has also been observed in the $\mathrm{Nd}_{3}(\mathrm{Fe}, \mathrm{Ti})_{29}$ compound and has been explained as a spin reorientation by Morellon et al [16]. The spin reorientation temperature, $T_{\mathrm{sr}}$, at which the spin reorientation occurs was derived from the peak position. The value of $T_{\text {sr }}$ increases with Er content from $158 \mathrm{~K}$ for $x=0$ to $198 \mathrm{~K}$ for $x=0.4$ as shown in figure $4(a)$. It is worth noting that the anomaly vanishes when the (040) reflection is surpassed by the (30-4) reflection in the XRD pattern of the aligned sample, namely when the tilt angle of the EMD with respect to the basal plane of $1: 5$ structure is big enough.

Figure 3 shows the TMA of the $\left(\mathrm{Nd}_{1-x} \mathrm{Er}_{x}\right)_{3} \mathrm{Fe}_{25} \mathrm{Cr}_{4.0}$ compounds measured in a temperature range from room temperature to above the Curie temperature. Curie temperatures $T_{\mathrm{c}}$ of $\left(\mathrm{Nd}_{1-x} \mathrm{Er}_{x}\right)_{3} \mathrm{Fe}_{25} \mathrm{Cr}_{4.0}$ are listed in table 1 . Figure 4(a) shows the composition dependence of $T_{\mathrm{c}}$. It can be seen that the Curie temperature, $T_{\mathrm{c}}$, decreases monotonically 


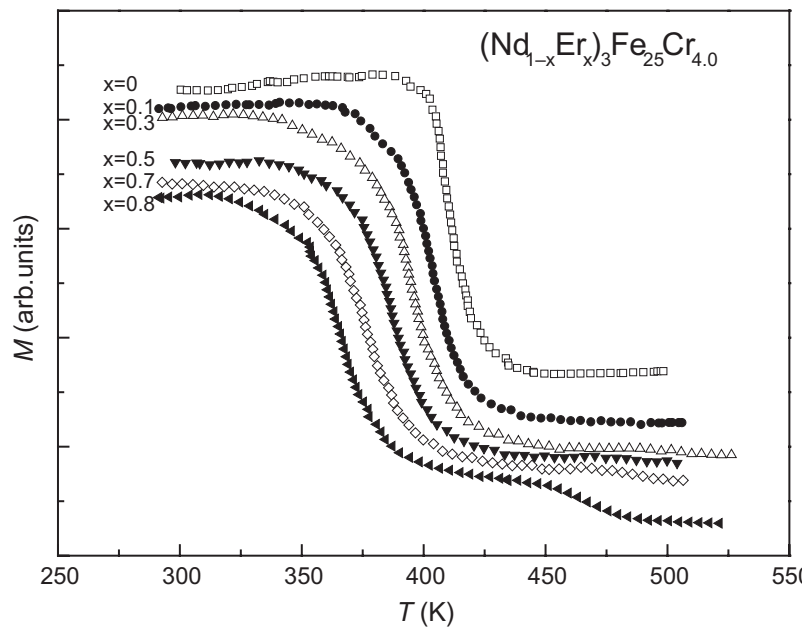

Figure 3. TMA of the $\left(\mathrm{Nd}_{1-x} \mathrm{Er}_{x}\right)_{3} \mathrm{Fe}_{25} \mathrm{Cr}_{4.0}$ compounds.

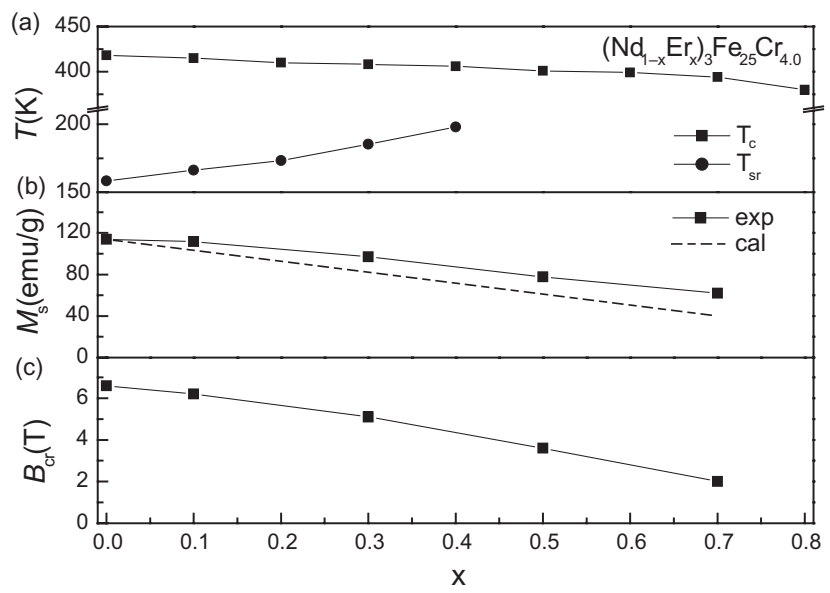

Figure 4. (a) Curie temperature, $T_{\mathrm{c}}$, and spin reorientation temperature, $T_{\mathrm{sr}} ;(b)$ saturation magnetization, $M_{\mathrm{s}}$; and $(c)$ critical field, $B_{\text {cr }}$, of the $\left(\mathrm{Nd}_{1-x} \mathrm{Er}_{x}\right)_{3} \mathrm{Fe}_{25} \mathrm{Cr}_{4.0}$ compounds as a function of the Er content.

with increasing $\mathrm{Er}$ content. It is well known that for the $\mathrm{R}-\mathrm{T}$ intermetallic compounds the Curie temperature, $T_{\mathrm{c}}$, is determined by the $\mathrm{T}-\mathrm{T}, \mathrm{R}-\mathrm{T}$, and $\mathrm{R}-\mathrm{R}$ interactions. Among them, the $\mathrm{T}-\mathrm{T}$ interaction is dominant, whereas the $\mathrm{R}-\mathrm{R}$ interaction is of minor importance and can usually be neglected. Because the transition metal content is fixed in the $\left(\mathrm{Nd}_{1-x} \mathrm{Er}_{x}\right)_{3} \mathrm{Fe}_{25} \mathrm{Cr}_{4.0}$ compounds and only the $\mathrm{Nd}$ and $\mathrm{Er}$ contents vary, the change in the Curie temperature is mainly determined by the R-T interaction. Based on the molecular field model, the Curie temperature, $T_{\mathrm{c}}$, can be expressed as [17]

$$
T_{\mathrm{c}}=\frac{1}{2}\left[T_{\mathrm{T}}+\left(T_{\mathrm{T}}^{2}+4 T_{\mathrm{RT}}^{2}\right)^{1 / 2}\right] .
$$

Here

$$
T_{\mathrm{T}}=n_{\mathrm{TT}} N_{\mathrm{T}}\left[\frac{4 S^{*}\left(S^{*}+1\right) \mu_{\mathrm{B}}^{2}}{3 k_{\mathrm{B}}}\right],
$$

$$
\begin{aligned}
T_{\mathrm{RT}}= & n_{\mathrm{RT}}|\gamma|\left(N_{\mathrm{T}} N_{\mathrm{R}}\right)^{1 / 2} \\
& \times\left[\frac{2\left(S^{*}\left(S^{*}+1\right)\right)^{1 / 2} \times g_{J}\left(J_{\mathrm{R}}\left(J_{\mathrm{R}}+1\right)\right)^{1 / 2} \mu_{\mathrm{B}}^{2}}{3 k_{\mathrm{B}}}\right],
\end{aligned}
$$

where $\gamma=2\left(g_{J}-1\right) / g_{J} \cdot 2\left(S^{*}\left(S^{*}+1\right)\right)^{1 / 2} \mu_{\mathrm{B}}$ is the effective moment of the iron atom in the paramagnetic state and $N_{\mathrm{T}}, N_{\mathrm{R}}$ are the number of $\mathrm{Fe}$ and $\mathrm{R}$ atoms per unit volume. $g_{J}$ and $J_{\mathrm{R}}$ are the Lande factor and the total angular moment of the rare-earth atoms, respectively. $T_{\mathrm{T}}$ and $T_{\mathrm{RT}}$ are the interaction coefficients of T-T and T-R, which stand for the contributions of the T-T and T-R interactions to $T_{\mathrm{c}}$. In equation (2), the $T_{\mathrm{RT}}^{2}$ is proportional to the de Gennes factor $\left(G_{J}(J)\right)$ of the R ion, where $G_{J}(J)=\left(g_{J}-1\right)^{2} J_{\mathrm{R}}\left(J_{\mathrm{R}}+1\right)$. It is well known that the value of $G_{J}(J)$ decreases as the atomic number in the series of heavy rare-earth elements increases, and the $G_{J}(J)$ value of Er is larger than that of Nd. Since the atomic radius of Er is smaller than that of $\mathrm{Nd}$ due to the lanthanide contraction, substitution of $\mathrm{Er}$ for $\mathrm{Nd}$ leads to a decrease of the unit cell volume and an increase in the values of $N_{\mathrm{T}}$ and $N_{\mathrm{R}}$. On the other hand, $n_{\mathrm{RT}}$ decreases as the atomic number of the rareearth elements rises. So the value of $n_{\mathrm{RT}}$ should decrease with Er substitution. The dependence of $T_{\mathrm{c}}$ on the composition may result from the competition of all these factors mentioned earlier.

The magnetization curves of the $\left(\mathrm{Nd}_{1-x} \mathrm{Er}_{x}\right)_{3} \mathrm{Fe}_{25} \mathrm{Cr}_{4.0}$ compounds with $x=0-0.7$ were obtained at $5 \mathrm{~K}$ in a field up to $5 \mathrm{~T}$, applied either parallel or perpendicular to the alignment direction, as shown in figure 5. Figure 6 shows the magnetization curves of the $\left(\mathrm{Nd}_{1-x} \mathrm{Er}_{x}\right)_{3} \mathrm{Fe}_{25} \mathrm{Cr}_{4.0}$ compounds measured at $5 \mathrm{~K}$ using PPMS with the applied field perpendicular to the alignment direction of the samples. It can be seen that the magnetization curves for the compounds from $x=0$ to 0.7 show a jump-like increase at certain fields. This phenomenon has also been observed in $\mathrm{Tb}_{3}(\mathrm{Fe}, \mathrm{V})_{29}$ [18] and has been explained as a first order magnetization process (FOMP), which arises from a magnetic field induced spin phase transition from one spin phase to the another. The critical field, $B_{\mathrm{cr}}$, at which the FOMP occurs was derived from the maximum of the $\mathrm{d} M / \mathrm{d} H$ versus $H$ curve. The values of $B_{\text {cr }}$ are listed in table 1. Figure 4(c) shows the value of $B_{\mathrm{cr}}$ as a function of Er content $(x)$. The critical field of the FOMP decreases with increasing Er content from 6.6 T for $x=0$ to 2.0 T for $x=0.7$.

The values of the saturation magnetization, $M_{\mathrm{s}}$, at $5 \mathrm{~K}$ are derived and listed in table 1 . Figure $4(b)$ shows the composition dependence of $M_{\mathrm{s}}$. It can be seen that the $M_{\mathrm{s}}$ value decreases monotonically with increasing Er content due to antiparallel coupling between the $\mathrm{Er}$ and $\mathrm{Fe}$ moments. Considering that the Er moment is antiparallel to the Fe and Nd moments and assuming that all the moments are collinear, the saturation moments, $M_{\mathrm{s}}$, of the $\left(\mathrm{Nd}_{1-x} \mathrm{Er}_{x}\right)_{3} \mathrm{Fe}_{25} \mathrm{Cr}_{4.0}$ compounds can be expressed as

$$
M_{\mathrm{s}}=M_{0}-3 x\left(\mu_{\mathrm{Nd}}+\mu_{\mathrm{Er}}\right) \text {, }
$$

where $M_{0}$ is the moment of $\mathrm{Nd}_{3} \mathrm{Fe}_{25} \mathrm{Cr}_{4.0}$ and $\mu_{\mathrm{Nd}}$ and $\mu_{\mathrm{Er}}$ are the average magnetic moments of the $\mathrm{Nd}$ and $\mathrm{Er}$ atoms, respectively. Assuming that the $\mu_{\mathrm{Nd}}$ and $\mu_{\mathrm{Er}}$ have free atomic moments of $3.62 \mu_{\mathrm{B}}$ and $9.59 \mu_{\mathrm{B}}$, respectively, taking the value of $M_{0}$ to be $113.9 \mathrm{~A} \mathrm{~m}^{2} \mathrm{~kg}^{-1}$, the values of $M_{\mathrm{s}}$ were calculated and are shown in figure $4(b)$ by the dashed line. It is seen that the calculated result is lower than the experimental one. This may be due to changes in the moments of the free $\mathrm{Er}$ and $\mathrm{Nd}$ ions as a result of the crystal field effect. 


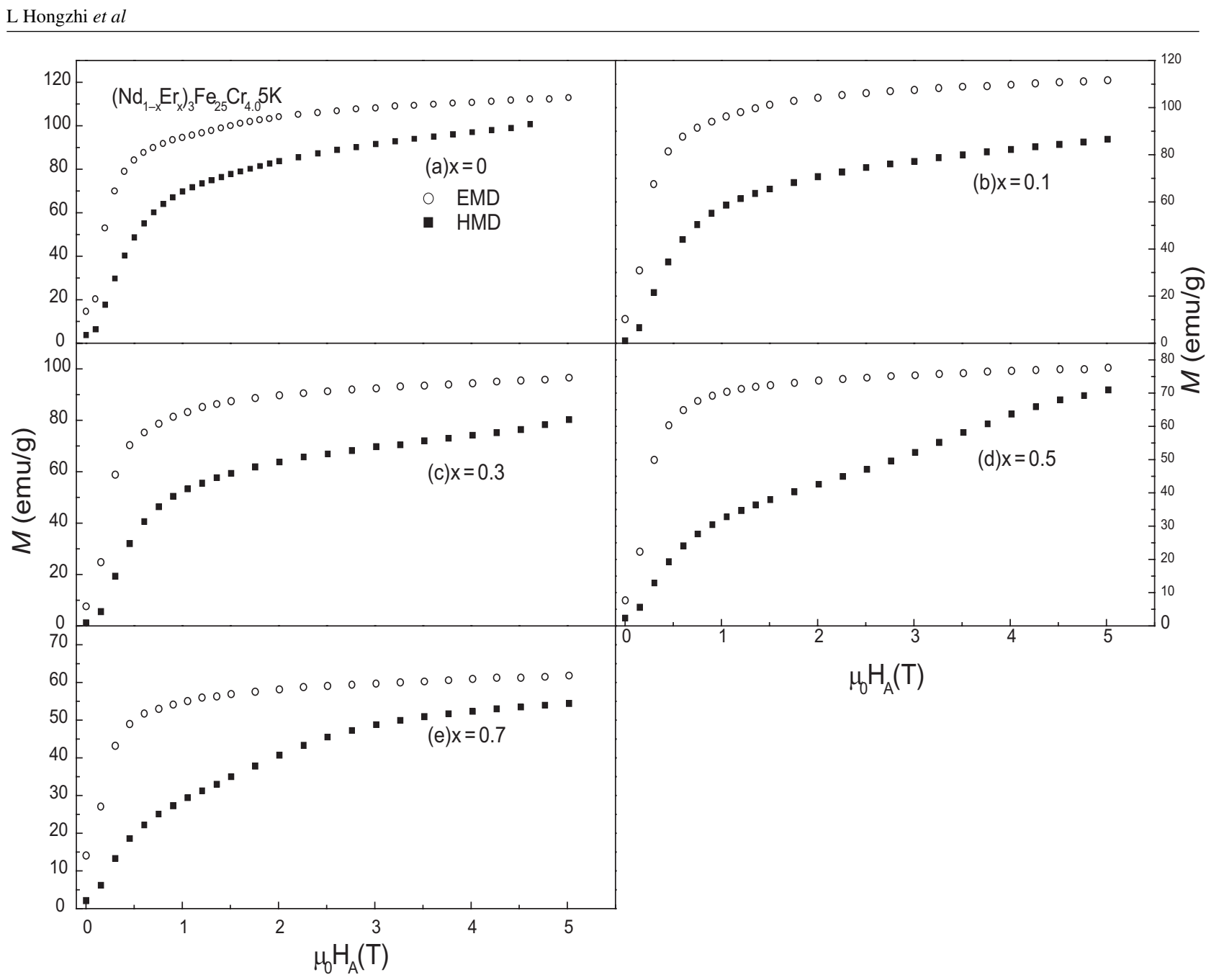

Figure 5. Magnetization curves of $\left(\mathrm{Nd}_{1-x} \mathrm{Er}_{x}\right)_{3} \mathrm{Fe}_{25} \mathrm{Cr}_{4.0}$ compounds.

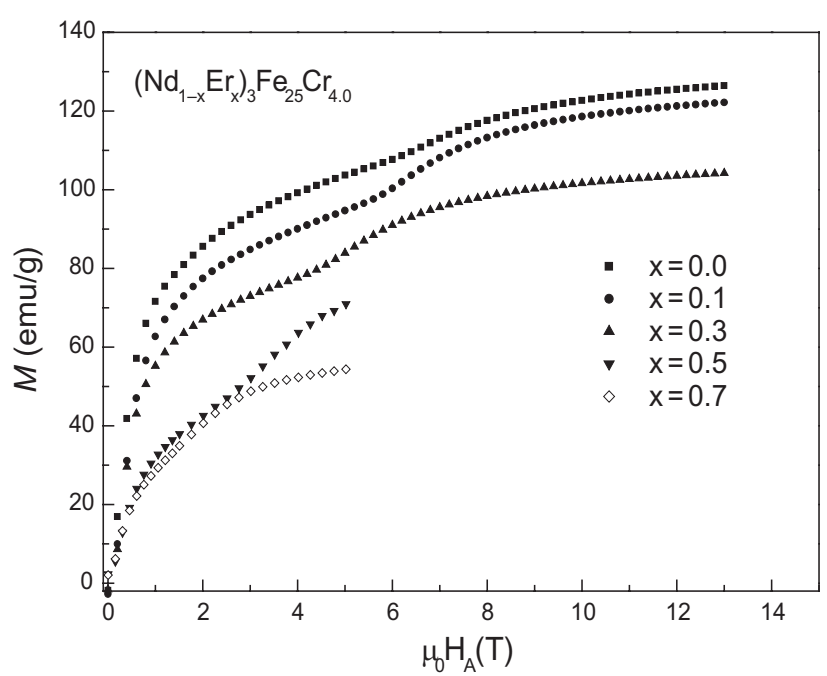

Figure 6. Magnetization curves of the HMD samples of $\left(\mathrm{Nd}_{1-x} \mathrm{Er}_{x}\right)_{3} \mathrm{Fe}_{25} \mathrm{Cr}_{4.0}$ compounds in a field up to $13 \mathrm{~T}$.

\section{Conclusion}

The structure and magnetic properties of $\left(\mathrm{Nd}_{1-x} \mathrm{Er}_{x}\right)_{3} \mathrm{Fe}_{25} \mathrm{Cr}_{4.0}$ compounds with $x=0-0.8$ have been investigated. It has been found that all the investigated compounds crystallize in a $\mathrm{Nd}_{3}(\mathrm{Fe}, \mathrm{Ti})_{29}$-type structure. Substitution of $\mathrm{Er}$ for $\mathrm{Nd}$ leads to a contraction of the unit-cell volume. The Curie temperature, $T_{\mathrm{c}}$, and the saturation moments, $M_{\mathrm{s}}$, of $\left(\mathrm{Nd}_{1-x} \mathrm{Er}_{x}\right)_{3} \mathrm{Fe}_{25} \mathrm{Cr}_{4.0}$ compounds decrease monotonically with increasing Er content. With increasing Er content the EMD changes from a direction close to the [040] direction to one close to the [40-2] direction but always makes a tilt angle with respect to the basal plane. Both the XRD patterns and ac susceptibility of the $\left(\mathrm{Nd}_{1-x} \mathrm{Er}_{x}\right)_{3} \mathrm{Fe}_{25} \mathrm{Cr}_{4.0}$ samples indicate a spin reorientation phenomenon for $x=0-0.4$ as the temperature decreases from room temperature to $77 \mathrm{~K}$. The spin reorientation temperature, $T_{\mathrm{sr}}$, increases monotonically with increasing Er content from $158 \mathrm{~K}$ for $x=0$ to $198 \mathrm{~K}$ for $x=0.4$. The FOMP occurs in all the compounds, and the critical field of the FOMP decreases with increasing Er content from $6.6 \mathrm{~T}$ for $x=0$ to $2.0 \mathrm{~T}$ for $x=0.7$.

\section{Acknowledgment}

This work was supported by State Key Project of Fundamental Research Grant, China (No G2000067106). 


\section{References}

[1] Collocott S J, Day R K, Dunlop J B and Davis R K 1992 Proc. 7th Int. Symp. on Magnetic Anisotropy and Coercivity in Rare Earth Transition Metal Alloys (Canberra, 1992) p 437

[2] Hu Z and Yelon W B 1994 J. Appl. Phys. 766147

[3] Yang F M, Nasunjilegal B, Pan H G, Wang J L, Zhao R W, Hu B P, Wang Y Z, Li H S and Cadogan J M 1994 J. Magn. Magn. Mater. 135298

[4] Fuerst C D, Pinkerton F E and Herbst J F 1994 J. Appl. Phys. 766144

[5] Cadogan J M, Hong-Shuo L, Margarian A, Dunlop J B, Ryan D H, Collocott S J and Davis R L 1994 J. Appl. Phys. 766138

[6] Han X F, Pan H G, Liu H L, Yang F M and Zheng Y W 1997 Phys. Rev. B 568867

[7] Ibarra M R, Morellon L, Blasco J, Pareti L, Algarabel P A, Garcia J, Albertini F and Paoluzzi A 1994 J. Phys.: Condens. Matter 6 L717

[8] Kalogirou O, Psychcharis V, Saettas L and Niarchos D 1995 J. Magn. Magn. Mater. 1451

[9] Yang F M et al 1994 J. Appl. Phys. 761971
[10] Hu B P, Liu G C, Wang Y Z, Nasunjilegal B, Tang N, Yang F M, Li H S and Cadogan J M 1994 J. Phys.: Condens. Matter 6 L595

[11] Li W X, Guo J G, Liu B D, Shen J, Wu G H, Chen N X and Yang F M 2004 Phys. Rev. B 69174427

[12] Courtois D, Li H S and Cadogan J M 1996 Solid State Commun. 98565

[13] Li H S, Cadogan J M, Hu B P, Yang F M, Nasunjilegal B, Margarian A and Dunlop J B 1995 J. Magn. Magn. Mater. 1441037

[14] Tang N, Kou X C, de Boer F R, Buschow K H J, Wang J L and Fuming Y 1999 J. Phys.: Condens. Matter 115313

[15] Sheloudko N, Gjoka M, Kalogirou O, Niarchos D, Skumryev V, Hadjipanayis G, Surinach S and Munoz J S 2003 J. Alloys Compounds 35273

[16] Morellon L, Pareti L, Algarabel P A, Albertini F and Ibarra M R 1994 J. Phys.: Condens. Matter 6 L379

[17] Belorizky E, Fremy M A, Gavigan J P, Givord D and Li H S 1987 J. Appl. Phys. 613971

[18] Courtois D, Li H S, Cadogan J M, Givord D and Bourgeat-Lami E 1997 IEEE Trans. Magn. 333844 